\title{
The Lepra Evaluation Project (LEP) an epidemiological study of leprosy in Northern Malaŵi. I: Methods
}

\author{
J M PONNIGHAUS, ${ }^{*}$ P E M FINE, $\dagger$ L BLISS, $\dagger$ \\ I J SLINEY, $\ddagger$ D J BRADLEY $\dagger \&$ R J W REES $\S$ \\ * Lepra Evaluation Project, P.O. Box 46, Chilumba, Karonga \\ District, Malâwi; $\dagger$ Ross Institute, London School of Hygiene and \\ Tropical Medicine, Keppel Street, London WC1; $\ddagger$ Department of \\ Epidemiology, Tulane University, 1430 Tulane Avenue, New \\ Orleans, LA 70112, USA; § Clinical Research Centre, Division of \\ Communicable Diseases, Watford Road, Harrow, Middlesex
}

\section{Accepted for publication 25 March 1987}

\begin{abstract}
Summary The methodology employed in a total population survey carried out by the Lepra Evaluation Project (LEP) in Karonga District, Northern Malawi (Central Africa) is described in detail. After a pilot study in 1979, the survey started in March 1980 and was completed in August 1984. Four (later 5) field teams visited households systematically across the district. Approximately 112,000 people were interviewed and examined. Preliminary analysis indicates that $98 \%$ of individuals resident in the survey area who could and should have been examined for clinical leprosy were examined. Completeness of examination of women varied according to the sex of the paramedical examiners. The methods of collection and processing of extensive data concerning a variety of possible risk factors for Mycobacterium le prae transmission and clinical disease are described. The paper serves as a background to a series of publications on various aspects of leprosy.
\end{abstract}

\section{Introduction}

Leprosy is perhaps the least understood of all the major infectious diseases of man. Our ignorance is particularly great with reference to its epidemiology. Though Mycobacterium leprae has been accepted as the aetiological agent for over a century, the sources and modes of transmission remain controversial, the extent of infection in endemic communities remains unknown and the pattern of disease is still unexplained.

There are several reasons for our poor understanding of the epidemiology of leprosy. ${ }^{\prime}$ Some of these are technical-in particular the problem of identifying $M$. leprae infection as distinct from clinical disease. Some are a function of the natural history of leprosy - the long incubation period makes it difficult to relate infection events with ultimate disease. Some are social-the stigma of the disease may disrupt households and cause selective migration so as to obscure situations associated 
with infection and early development of disease. And other reasons are operational-leprosy is uncommon even in populations most highly endemic for the disease, and the low prevalence and incidence mean that very large populations must be studied in order to arrive at precise estimates of disease frequency.

Given such difficulties, it is not surprising that there have been relatively few thorough epidemiological studies of the disease. The first such studies were those of Doull, carried out in the Philippines during the 1930s. These began as house-to-house surveys in 2 municipalities where leprosy was endemic, and involved the collection of retrospective information from household members, as well as prospective information obtained by follow-up over subsequent years. ${ }^{2,3}$ Data thus collected were used to measure factors associated with increased risk of disease, such as crowding and contact; and these studies provided the first careful description of population patterns of leprosy. Other important epidemiological studies include the analyses of data collected in repeated general population surveys in Karigiri, South India ${ }^{4.5}$ and in BCG trials against leprosy in Uganda, ${ }^{6}$ Burma ${ }^{7.8}$ and New Guinea. ${ }^{9}$ The recent analysis of data from the Norwegian Leprosy Register by Irgens ${ }^{10}$ represents another important contribution to our understanding of leprosy, in this case in a population from which the disease was disappearing. It is notable that of all these studies, only those of Doull were designed expressly to study the pattern and risk factors underlying leprosy, whereas the others arose as a concomitant of data collected for either control, vaccine trial or official registration purposes.

A major stumbling block to understanding the population pattern of leprosy has been our inability to recognize infection with $M$. leprae. But recent years have witnessed the development of several tools with the potential for detecting infection on a population scale: for example the preparation of soluble antigens from $M$. leprae for use as skin test reagents, and the refinement of a number of serological tests for recognition of antibodies to $M$. leprae. The potential of these tests to reveal the underlying pattern of $M$. leprae infection, and hence to reveal risk factors for infection and further transition from infection to clinical leprosy was recognized in the late 1970s by the British Leprosy Relief Association (LEPRA). These methods were incorporated into the plans for a large epidemiological study in Karonga District, Northern Malawi. This study became known as the LEPRA Evaluation Project (LEP). The purpose of the LEP was to study the natural history of leprosy in an endemic area and to evaluate the effectiveness of ongoing methods for its control.

In this paper we describe the methods used by the LEP. It will serve as a background to a series of publications on various aspects of leprosy. In addition it is hoped that this detailed presentation of the methods involved in the LEP survey will prove helpful to others who may contemplate population studies of leprosy or other diseases.

\section{Project area}

Karonga District lies along the shore of Lake Malawii (Figure 1). The population in 1979 numbered approximately 113,000 people, most of whom were and still are engaged in subsistence farming. ${ }^{11}$ There were five main reasons for the choice of Karonga District for the project. First, Karonga District provided a well defined and somewhat isolated area with clear natural boundaries to the east (Lake Malawi) and to the west (the escarpment of the Central African Plateau). The boundary to the north (the Songwe river) is an international frontier. and only towards the south, towards Rumphi District and the Henga valley, is the boundary of Karonga District entirely open. Second, it was estimated from records of the LEPRA Control Project (see below) that the incidence rate in the area was likely to be of the order of 1 per thousand per year. This was thought to be sufficient for the epidemiological study as envisaged. Third, the experience of this control project made it seem likely that people would welcome and co-operate with the study. Fourth, housing, office space, garages and other infrastructural requirements for the evaluation project were available at the headquarters of the Lepra Control Project in Chilumba. Finally, the Government of the Republic of Malawi encouraged the setting up of the project. 


\section{LEP - KPT}

(Lepra Evaluation Project - Karonga Prevention Trial) KARONGA DISTRICT. NORTHERN MALAWI

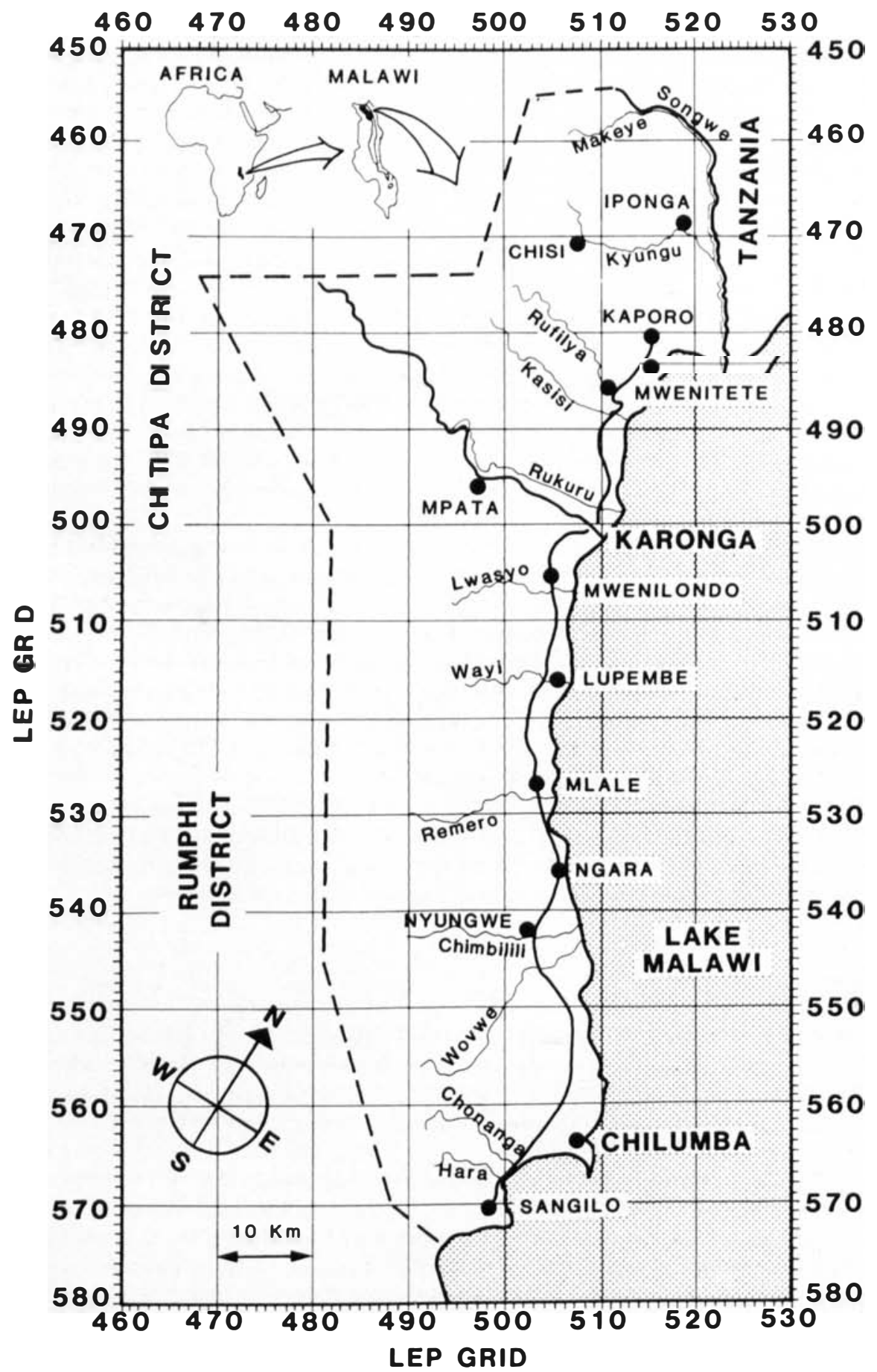

Figure 1. Map of Karonga District, Northern Malawii. LEP Project Headquarters is located at Chilumba. The 1979 Pilot Project was carried out near Mwenilondo near the centre of the District. The kilometre grid was drawn on 1:10,000 aerial photographs for coordinate location of households. 
The District consists of a flat stretch of land of varying width (never more than $8 \mathrm{~km}$ ) along the lake, and a larger sparsely inhabited stretch of hills along the edge of the Central African Plateau. The main food crops are cassava, maize and rice. In addition, ground nuts, sweet potatoes, millet and bananas are grown. The main cash crops are rice, maize and cotton.

The main ethnic groups are the Kyangonde speaking people, who live mainly north of Mlale and the Chitumbuka speaking people who form several communities in the North of the District but mostly live from Mlale southwards (Figure 1).

\section{Historical context}

There was no formal leprosy control programme in the District prior to 1973, though some antileprosy treatment had been given to leprosy patients by the General Health Services staff at the district hospital and at health centres. In that year a leprosy control project was introduced under the aegis of LEPRA. ${ }^{12}$ This was part of the LEPRA Control Project (LCP) for the Northern Region of Malawi, under the direction of Dr G Boerrigter. A mobile service was built up for the whole of Karonga district and was in operation towards the end of 1973. Trained paramedical workers (Leprosy Control Assistants, LCAs) were based in Karonga and Chilumba. They were responsible for examining any individuals who self-reported with suspected signs of clinical leprosy, for registering patients and for supervising their treatment, which was given weekly or bi-weekly by so called Clinic Attendants (CAs). The control procedures and drug regimens are described in detail in an earlier study. ${ }^{12}$

Records of all registered leprosy patients were kept by the LCAs (originals) and in the office in Chilumba (copies). Each time an LCA made an entry on the original record (c.g. review notes) he was meant to send that record to the office so that a clerk could enter the note onto the office copy.

Slit-skin smears were taken from all suspected cases of multibacillary leprosy and from BB, BL and LL patients. One smear was taken from each earlobe and 2 smears from the most active lesion(s). ${ }^{12}$ The smears were examined by a microscopist in Chilumba. Degrees of positivity were expressed as Bacterial Index (BI) in accordance with the logarithmic scale suggested by Ridley. ${ }^{13}$ In addition the microscopist reported on the proportion of solid staining $(\mathrm{S})$, fragmented $(\mathrm{F})$, and granulated (G) acid-fast bacilli (SFG\%). ${ }^{12}$

From 1973 to 1979 inclusive, the LEPRA Control Project had registered 490 male and 582 female, previously untreated, new leprosy patients in Karonga District. It should be emphasized that these cases were detected passively, except for a small number detected during school and contact surveys. The precise number detected during such surveys is unknown.

\section{Pilot project}

A pilot project was set up in 1979 to assess whether the frequency of leprosy in Karonga District was indeed high enough to support the envisaged epidemiological project, and whether people would cooperate with the study. In addition it was necessary to develop and test field methods, questionnaires and data handling procedures, on a small scale, before finalizing the main study protocol.

A group of villages around Mwenilondo, in the centre of Karonga District, was chosen for the pilot project (see Figure 1). This choice was made for three reasons: first, for reasons of etiquette, because the villages were in the area of Chief Kyungu, the oldest chieftaincy in Karonga District (dating back to the 16th century); secondly, for logistic reasons in so far as there were insufficient funds to carry out a proper random sample throughout the district; and third, because the villages were centrally located and LCP treatment registers suggested that there might be a gradient in leprosy prevalence from north to south within the district. On the basis of preliminary tabulations 
from the 1977 Malawi population census it was expected that about 3000 people lived in this group of villages. " The number of known leprosy patients was not considered when choosing the area.

In the pilot study, 3018 people were interviewed and examined. Twenty-one leprosy patients known to the LCP were found and another 30 were newly discovered by the LEP team. Of the 30 newly discovered leprosy patients, 8 were long-standing cases who had received some antileprosy treatment before the LCP had started in Karonga District. These findings confirmed that a considerable proportion of all leprosy patients in Karonga District were not yet known to the control project, and suggested that the true incidence rate of clinical leprosy might even be greater than 1 per 1000 person years in Karonga District.

Co-operation from the people during the Pilot Project was excellent. Thus, after considerable revision of procedures and questionnaires, the main study was started in 1980.

\section{Main study (LEP-1)}

The initial LEP survey (called LEP-1) lasted more than 4 years (March 1980-August 1984) and entailed the systematic survey of almost the entire district, with the exception of the southern tip and the area projecting into Chitipa district (Figure 1).

People were examined in their homes. They were not asked to gather at a central meeting point because it was evident that a high coverage could not be achieved in that way.

The work was carried out initially by 4 teams, increased to 5 in February 1983. Each team consisted of 2 (occasionally 3) LCAs or LCA trainees, 2 (at times 1) interviewers and a cook/camp attendant. They lived in tents. A team was moved to the next site after completing the examination of a village, part of a village or cluster of villages, depending on the distances involved to reach the furthest households. It was thought that the staff should not have to travel more than 20 minutes by bicycle to reach the furthest households, so that they would readily go again to interview and examine any members who had been missed on the first occasion. In the hills along the western boundary of the survey area the teams had sometimes to walk several hours to reach a group of households in some small valley. In these circumstances they might remain overnight in one of the households before returning to their camp.

A team was expected to interview and examine $25-30$ people a day, $4 \frac{1}{2}$ days per week. The timetable was determined by the necessity to read skin tests 3 days after injection. For this reason, Thursdays were set aside for the staff to arrange with heads of households suitable times for the examination of their households, to look for people who had been missed, to review people together with the Medical Officer (and to wash their uniforms and service their bicycles).

\section{Interviewing}

A household was defined as a group of people living together and acknowledging 1 person as its head. Given the polygamous nature of the society in Karonga District, this definition implied that if the wives of 1 man lived in different places then he could be the head of several households. Members of 1 household would frequently not eat together, but share their meals only with those with whom they shared a dwelling. Thus though communal eating and sleeping under the same roof has been used for defining a household in other societies ${ }^{14}$ it did not seem to provide a suitable definition of Karonga District. The main circumstance under which our definition proved unsatisfactory was when a newly married son had not (yet) left his father's household. He would normally (traditionally) leave at the time of marriage because daughters-in-law should not see their fathers-in-law face to face. If a married son continued to stay with his father it was not always obvious whether the son still acknowledged his father as head, whether he felt himself to be already the head of his own household, or whether his father, because of ill health or very old age, had 
Table 1. Variables included on the LEP-1 Household Questionnaire

\author{
Household serial number (pre-printed, 5 digit) \\ Name of household head \\ Village \\ Number of dwellings \\ Geographic coordinates (location numbers) \\ Languages spoken \\ Year of arrival of the household in this place \\ Previous place of residence of the household \\ Ownership with regard to main dwelling (owned, rented etc) \\ Items owned by household members (e.g. radio, bicycle etc) \\ Presence of pit latrine \\ Membership in agricultural development scheme \\ Ownership (and number) of cattle \\ Ownership of Kraal or stable \\ Ownership of work oxen, ox cart, metal plough \\ Number of traditional grain stores \\ Number of boats owned (if one of members is a fisherman)
}

effectively handed over the headship to his son. In such situations the decision as to defining a household was left to the interviewers on an ad hoc basis. Traditional hospitals, camps and the prison in Karonga were also treated as 'households'.

The main dwelling of each household was identified on aerial photographs of the area, taken in 1978. Households which were established after the aerial photographs had been taken were located with reference to appropriate landmarks. A location number was given to each household in terms of geographic coordinates within a grid system specially designed for the project and drawn onto the photographs by cartographers at the Malawii Government Department of Surveys (Figure 1). The scale of the aerial photographs $(1 \mathrm{~cm}=100 \mathrm{~m})$ usually permitted each dwelling to be located to within $10 \mathrm{~m}$.

The interviewers began by completing a 'Household Questionnaire', obtaining the information from the head or, in his absence, a senior member of the household. The main variables included on this questionnaire are listed in Table 1.

The interviewers then turned to each member of the household (or, in the case of small children, their parents) and completed a separate 'Personal (Alive and Present) Questionnaire' for each individual. The main variables are listed in Table 2.

It was decided to obtain information on the parents of each living person interviewed, to assist in their future identification and to permit the linking of genetically related individuals. Thus for parents who were dead, or alive but not in this household, separate 'Personal (Dead or Absent) Questionnaires' were filled in. These were restricted to basic identifying information. In addition to completing these questionnaires the interviewers drew a pedigree for each household to facilitate orientation during interviewing and coding.

A particularly important feature of these personal questionnaires was the identification ('IDENT') number. Each personal questionnaire carried a unique, pre-printed, 6-digit IDENT number, and each individual became identified permanently in project records by the number on his or her 'first' questionnaire. In order to avoid transcription and keypunch errors with this crucial number, a 7th digit was added as a check digit, determined by an algorithm based on the initial 6 digits (see Table 3 ).

As part of the interviews, all individuals above the age of 7 years were asked whether they had had a cough for more than 1 month. If an individual reported such a cough and could produce sputum, his or her sputum was collected on that occasion and a further container was left behind with instructions for the individual to expectorate into it first thing the following morning. 
Table 2. Main variables included on LEP-1 Personal (Alive and Present) Questionnaire

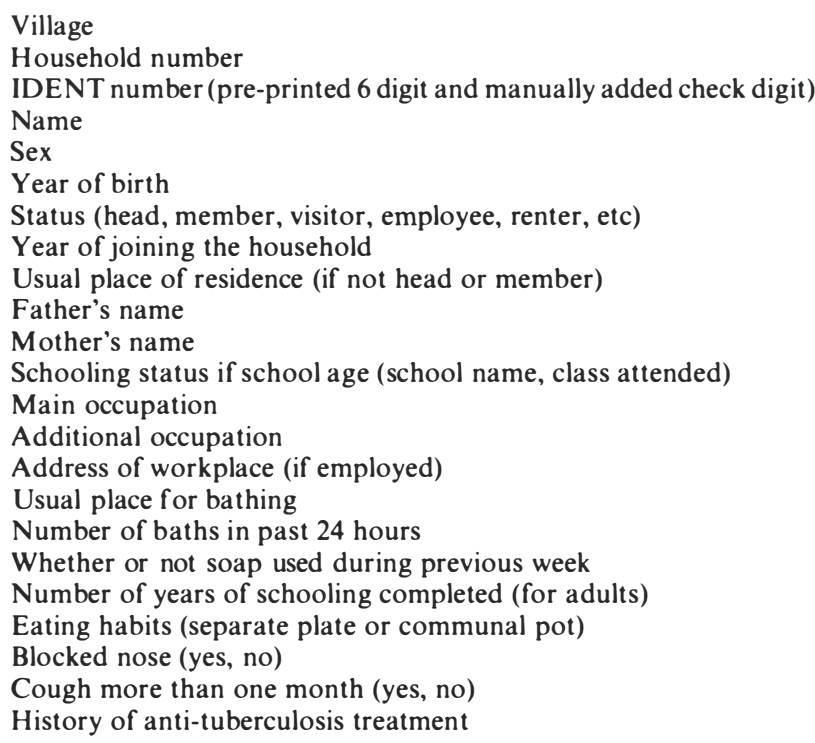

Table 3. Algorithm for derivation of check digits for IDENT numbers used in LEP

1 Take 6-digit ident, eg

2 Multiply the first, third and fifth-digits from the left by 2, and write the units digits of the answers under the original digits

3 Multiply the second and sixth digits from the left by 6 , and write the units digits of the answers under the original digits

4 Multiply the fourth digit from the left by 4 , and write the units digit of the answer under the original digits

5 Add the 6-digit numbers:

$$
140378
$$

240248

380626

6 Add the digits of the answer together: $3+8+0+6+2+6=25$

7 Subtract this from the next highest multiple of 10 , which in this example is 30 :

$$
30-25=5
$$

8 The result, 5, is the check digit, and becomes the seventh digit of the completed IDENT: eg 140378-5

The interviewers finally filled in a 'Dwelling Questionnaire'. A dwelling was defined as any structure in which someone usually slept. The various types can be seen in Table 4 . The interviewers were required to note any useful particulars of absent individuals reported as sleeping in a dwelling, but who did not belong to the household, in order to facilitate their tracing.

All questions were asked in a standard form in either Kyangonde or Chitumbuka (or occasionally in Swahili, Kinyakyusa, or Chilambia). Only if the standard question was not 
Table 4. Main variables included on LEP-1 Dwelling Questionnaire

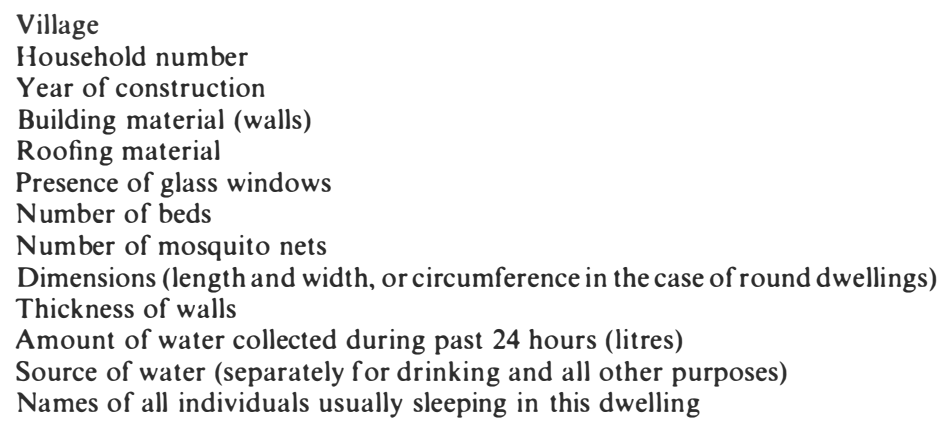

Table 5. Main dates used in LEP-1 Local events calendar

\begin{tabular}{ll}
\hline Year & \multicolumn{1}{c}{ Event } \\
\hline 1914 & Battle of Karonga (World War I) \\
1934 & Major locust plague \\
1946 & Passenger ship Vipya sank \\
1958 & His Excellency returned to Malawi Nyasaland) \\
1964 & Independence of Malawi \\
\hline
\end{tabular}

sufficiently understood was the wording varied. Interviewers were initially supervised by the Medical Officer and later usually by a Senior Interviewer.

Local events calendars were used in order to assign periods of time to births, to entry into or establishment of households (and to the onset of lesions) whose dates were not known or whose claimed dates were inconsistent with appearance or with other data. Periods were chosen with ref erence to well-known local events and were assigned on the basis of memories, appearances and in relation to other data collected in the household. The main events and dates used are shown in Table 5. This approach has been unavoidable, and has forced us to use irregular age and time groups in analysing and presenting data. The effect is illustrated in Figure 2, which shows the distributions of birth years of males and females interviewed in the survey. It is evident that an appreciable proportion of adults could not be assigned a precise year of birth, and that this proportion is higher for females than for males.

Considerable attention was given to quality control during the survey. In addition to supervision an effort was made to assess interobserver variation by organizing independent collection of data on several occasions. Table 6 shows the results of one such exercise, the independent assessment of birth year by field interviewers, and by the senior interviewer, of 323 individuals born since 1960 . In $94 \%$ of individuals the variation was within 1 year.

Completed questionnaires and any specimens (slit-skin smears, sputum and urine specimens) were usually carried to Chilumba on Saturday afternoons.

\section{General examinations}

Individuals were examined for leprosy by paramedical Leprosy Control Assistants (LCAs) on the same day shortly before or after being interviewed. The training of the LCAs consisted of a 6-week 
- Table 6. Example of quality control (interobserver variation) on birth year data as ascertained on 323 people during 1983 . Columns show birthyears as recorded by teams II and III under routine conditions, and rows show birth year estimates obtained independently by the senior interviewer. Complete agreement was found in $237(73.4 \%)$ individuals. In $21(6.5 \%)$ the disagreement was greater than 1 year

Year of birth as ascertained during routine interviewing by teams II and III

\begin{tabular}{|c|c|c|c|c|c|c|c|c|c|c|c|c|c|c|c|c|c|c|c|c|c|c|c|c|c|c|}
\hline & & 1983 & 82 & 81 & 80 & 79 & 78 & 77 & 76 & 75 & 74 & 73 & 72 & 71 & 70 & 69 & 68 & 67 & 66 & 65 & 64 & 63 & 62 & 61 & 60 & Total \\
\hline & 1983 & 14 & & & & & & & & & & & & & & & & & & & & & & & & 14 \\
\hline & 82 & 1 & 16 & & & & & & & & & & & & & & & & & & & & & & & 17 \\
\hline Year of & 81 & & 5 & 26 & 3 & & 1 & & & & & & & & & & & & & & & & & & & 35 \\
\hline birth as & 80 & & & 5 & 16 & 2 & & & & & & & & & & & & & & & & & & & & 23 \\
\hline ascertained by & 79 & & & & 4 & 16 & 4 & & & & & & & & & & & & & & & & & & & 24 \\
\hline the senior & 78 & & & & & 1 & 20 & 2 & 1 & & & & & & & & & & & & & & & & & 24 \\
\hline \multirow[t]{18}{*}{ interviewer } & 77 & & & & 1 & 1 & & 11 & 4 & & & & & & & & & & & & & & & & & 17 \\
\hline & 76 & & & & & 1 & 1 & 1 & 10 & 1 & 3 & & & & & & & & & & & & & & & 17 \\
\hline & 75 & & & & & & 1 & & 3 & 10 & 2 & & 1 & & & & & & & & & & & & & 17 \\
\hline & 74 & & & & & & & & & & 10 & 3 & 2 & & & & & & & & & & & & & 15 \\
\hline & 73 & & & & & & & & & & 2 & 12 & 2 & & & & & & & & & & & & & 16 \\
\hline & 72 & & & & & & & & & & & 2 & 16 & 2 & & & & & & & & & & & & 20 \\
\hline & 71 & & & & & & & & & & 1 & & 2 & 10 & 1 & & & & & & & & & & & 14 \\
\hline & 70 & & & & & & & & & & & & & 1 & 8 & & & & & & & & & & & 9 \\
\hline & 69 & & & & & & & & & & & & & & 1 & 6 & & 1 & & & & & & & & 8 \\
\hline & 68 & & & & & & & & & & & & & 1 & & 2 & 5 & & & & & & & & & 8 \\
\hline & 67 & & & & & & & & & & & & & & & 1 & & 5 & 1 & & & & & & & 8 \\
\hline & 66 & & & & & & & & & & & & & & & & & & 7 & 1 & & & & & & 8 \\
\hline & 65 & & & & & & & & & & & & & & & 1 & & & 1 & 1 & 1 & & & & & 4 \\
\hline & 64 & & & & & & & & & & & & & & & & & & & 2 & 6 & & 1 & & & 9 \\
\hline & 63 & & & & & & & & & & & & & & & & & & & & 1 & 5 & 1 & & & 7 \\
\hline & 62 & & & & & & & & & & & & & & & & & & & & & & 2 & & & 2 \\
\hline & 61 & & & & & & & & & & & & & & & & & & & 1 & & & & 3 & & 4 \\
\hline & 60 & & & & & & & & & & & & & & & & & & & & & & 1 & & 2 & 3 \\
\hline Total & & 15 & 21 & 31 & 24 & 21 & 27 & 14 & 18 & 11 & 18 & 17 & 23 & 14 & 10 & 10 & 5 & 6 & 9 & 5 & 9 & 5 & 5 & 3 & 2 & 323 \\
\hline
\end{tabular}



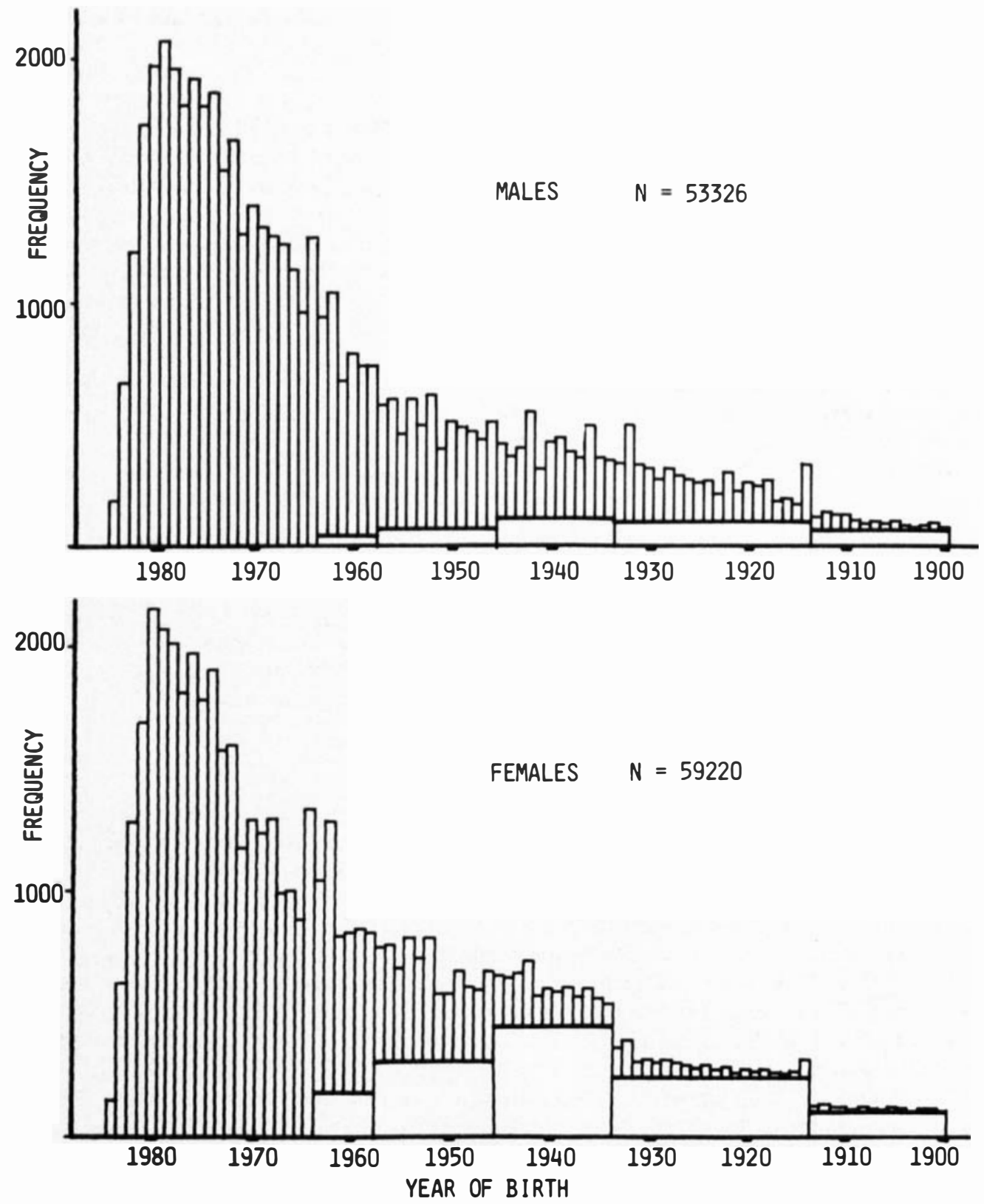

Figure 2. Distribution of birth years of males and females included in LEP-1 survey. Note that some individuals gave specific birth years (narrow bars), whereas the birth period had to be estimated for others using the local events calendar shown in Table 4 (wide bars).

course which gave them some theoretical knowledge of leprosy and its treatment. For an initial 6 months they then carried out all examinations under the supervision of a Medical Officer or a qualified LCA, until they were considered sufficiently competent not to overlook a suspicious skin lesion or an enlarged peripheral nerve (although undoubtedly this cannot be avoided entirely and will also happen with the most experienced examiner). 
Emphasis was placed on thoroughness of examinations. The LCAs were meant whenever possible to examine people together-one of them examining, and the other recording all findings on a 'General Examination Form'. The examination of more than 40 people per day was discouraged unless there were more than 2 LCAs in the team at the time.

The Leprosy Control Assistants had to complete the 2-page General Examination Form for every individual seen. The form included preprinted drawings into which the LCAs had to enter any findings which might be signs of leprosy and also the sites of any scars, birthmarks, fungus infections, eczema or other unusual findings. They had to indicate whether they considered the examination to have been complete or incomplete, or whether the individual ref used examination altogether. In the case of incomplete examinations the LCAs indicated on the form the part of the body which was inadequately examined. The LCAs also recorded the presence or absence of a BCG scar and graded the general cleanliness of the examined individuals on a 4-point scale from 'very clean' to 'very dirty'.

Nerves included in the routine examination of all individuals (except infants) were: the supraorbital zygomatic, greater auricular, supraclavicular, upper radial, upper ulnar, superficial radial, lower ulnar, peroneal and superficial peroneal nerves.

The LCAs also applied and read skin tests and obtained finger prick blood specimens as required. Methods used will be described in detail in subsequent publications devoted to the skin test and serology results.

Efforts were made to recruit female LCAs. However this proved to be difficult and there was rarely more than 1 female among the staff of 10-12 LCAs at any given time. The names or staff codes of all examiners present at each examination were recorded on the General Examination Forms, but only 2 were ultimately coded for analysis. Despite the fact that the coded data did not always identify all those examiners present at any one time, it was possible to investigate the effect of the sex of the examiner upon the completeness of examination (see below).

\section{Detailed examination}

Additional information was collected and a special 'Detailed Examination Form' completed by the examiner(s) for all individuals suspected to have, or to have had, clinical leprosy.

Any enlarged nerves or skin lesions suspected to be due to leprosy which were found by LCAs in individuals not already known to the LEPRA Control Project (LCP), or not known to have received antileprosy treatment elsewhere, led to the individual's being 'put on observation' to be seen by the Medical Officer (JMP) as soon as possible. Patients already known to the LCP, or who had received treatment elsewhere, were only 'put on observation to be seen by the MO' if the skin lesions were still active in spite of antileprosy treatment. The subsequent examination by the MO was called a 'Review Examination'. On any review a Detailed Examination Form was filled unless (a) the Medical Officer decided that the clinical signs were definitely not due to leprosy, or (b) the lesions had already disappeared.

For all leprosy patients already known to the LCP, Detailed Examination Forms were filled by the Leprosy Control Assistants on their own, unless the MO happened to be present. They also completed Detailed Examination Forms for any expatient who had received antileprosy treatment from an institution other than the LCP, provided signs of leprosy could still be found or the expatient let the staff know that he had once received antileprosy treatment.

Information collected on the Detailed Examination Form included a description of any lesions, peripheral nerve enlargement and/or disabilities. In addition the LCAs were meant to try to elicit the approximate year of onset of whatever signs had been found. This proved to be more difficult than with other dates in which we were interested. Some newly found patients tried to persuade us that a lesion had been present 'since birth' (perhaps in an attempt to persuade the staff that, because it had been there since birth, it could not be leprosy). Others gave us recent years of onset which 
turned out to be years after they had started to receive antileprosy treatment. On the other hand, the statement that a lesion had been present 'since childhood', but that it had started to grow only 'recently' was encountered so frequently on close questioning by the Medical Officer that we feel it should not be discounted altogether. It has made us sceptical about attempts to date the 'onset' of leprosy.

Slit-skin smears were taken by the LCAs from anyone with skin lesions which were considered as possibly due to multibacillary leprosy.. Not all of these individuals were seen by the MO, in particular if the slit-skin smear result was negative and paucibacillary leprosy was not included in the differential diagnosis. In addition LCAs were meant to take slit-skin smears from anyone with signs of leprosy and a history of having received antileprosy treatment, but who was not at that time known to the LCP. Not all these 'expatients' agreed to this. Known multibacilliferous patients registered with the LCP were usually not asked to agree to have slit-skin smears taken since we had access to the results of smears taken routinely every 6 months from such patients.

Smears were stained (Ziehl-Neelson) and examined at Project Headquarters. Positive smears of newly discovered leprosy patients were shown to the MO. Routine quality control was carried out by the LCP Laboratory Superintendent based in Lilongwe. ${ }^{12}$

When examining suspects a clinical certainty grade was given by the Medical Officer. Grades and criteria were rigorously defined and are discussed in detail in a separate paper. ${ }^{15}$ Here it may suffice to say that the grading was, in order of increasing clinical certainty: 'possibly leprosy', leprosy to be considered seriously', 'most likely leprosy', 'leprosy extremely likely', and 'leprosy certain'.

At the time of the household visit the LCAs were meant to collect urine specimens from all patients registered by the LCP for the analysis of the dapsone:creatinine ratios in the project laboratory.

\section{Completeness of examinations}

Data on completeness of examination have been analysed with reference to age and sex of examinee, and with reference to the sex of the examiners. This has shown that the examiners' sex was irrelevant for the examination of male but not of the female individuals. Thus, $98.95 \%$ of males were examined completely in the presence of a female LCA and $98.6 \%$ were completely examined in their apparent absence ('apparent' in so far as no female was included among the 2 coded examiners). However, whereas $98.6 \%$ of females agreed to complete examination in the presence of a female LCA, only $93.6 \%$ agreed to complete examination in those circumstances in which no female LCA was among the 2 coded examiners. The age specific rates of examination of females in the presence or absence of a female LCA among the coded examiners are shown in Table 7 and Figure 3. All examinations in which the Medical Officer was coded as one of the examiners are excluded from this analysis. The proportion completely examined falls consistently with age, but is appreciably higher in the presence of a female LCA, particularly for middle-aged and older females. If an examination was incomplete it usually meant that the buttocks and upper parts of the thighs were not seen.

\section{Data processing}

The overall data processing scheme for the LEP is shown in Figure 4. Household, dwelling unit, personal (alive and present) and personal (dead or absent) questionnaires and general examination forms were assembled in household order in the coding office at Project Headquarters. The information was checked for completeness, for internal consistency of the data and for consistency with information collected in related households. Requests for collection of missing information and for checking inconsistent data were sent back to the field teams on a weekly basis. 
Table 7. Numbers of complete examinations, incomplete examinations and examinations not done on females in the apparent absence of a medical officer, and in the presence or apparent absence of a female LCA. See Figure 3

\begin{tabular}{|c|c|c|c|c|c|c|c|c|}
\hline \multirow[b]{2}{*}{$\begin{array}{l}\text { Age at } \\
\text { examination }\end{array}$} & \multicolumn{4}{|c|}{ Apparent absence of a female LCA } & \multicolumn{4}{|c|}{ Presence of a female LCA } \\
\hline & $\begin{array}{c}\text { Complete } \\
\text { exams }\end{array}$ & $\begin{array}{c}\text { Incomplete } \\
\text { exams }\end{array}$ & $\begin{array}{c}\text { Exam } \\
\text { not done }\end{array}$ & Total & $\begin{array}{c}\text { Complete } \\
\text { exams }\end{array}$ & $\begin{array}{l}\text { Incomplete } \\
\text { exams }\end{array}$ & $\begin{array}{c}\text { Exam } \\
\text { not done }\end{array}$ & Total \\
\hline $0-4$ & $\begin{array}{c}7458 \\
(99 \cdot 8 \%)\end{array}$ & 10 & 7 & 7475 & $\begin{array}{c}2195 \\
(100 \%)\end{array}$ & 0 & 0 & 2195 \\
\hline $5-9$ & $\begin{array}{c}6610 \\
(99.9 \%)\end{array}$ & 5 & 4 & 6619 & $\begin{array}{c}1988 \\
(99.9 \%)\end{array}$ & 2 & 0 & 1990 \\
\hline $10-16$ & $\begin{array}{c}6308 \\
(98 \cdot 4 \%)\end{array}$ & 93 & 8 & 6409 & $\begin{array}{c}1969 \\
(99.6 \%)\end{array}$ & 6 & 2 & 1977 \\
\hline $17-22$ & $\begin{array}{c}3746 \\
(92 \cdot 3 \%)\end{array}$ & 293 & 18 & 4057 & $\begin{array}{c}1355 \\
(98.9 \%)\end{array}$ & 15 & 0 & 1370 \\
\hline $23-34$ & $\begin{array}{c}5849 \\
(89.6 \%)\end{array}$ & 631 & 51 & 6531 & $\begin{array}{c}2175 \\
(98.5 \%)\end{array}$ & 32 & 2 & 2209 \\
\hline $35-46$ & $\begin{array}{c}4786 \\
(87 \cdot 7 \%)\end{array}$ & 642 & 28 & 5456 & $\begin{array}{c}1666 \\
(97 \cdot 4 \%)\end{array}$ & 45 & 0 & 1711 \\
\hline $47-66$ & $\begin{array}{c}3678 \\
(84.9 \%)\end{array}$ & 625 & 27 & 4330 & $\begin{array}{c}1370 \\
(96 \cdot 6 \%)\end{array}$ & 45 & 3 & 1418 \\
\hline $67-80$ & $\begin{array}{c}939 \\
(80 \cdot 1 \%)\end{array}$ & 222 & 11 & 1172 & $\begin{array}{c}347 \\
(90 \cdot 8 \%)\end{array}$ & 34 & 1 & 382 \\
\hline$>80$ & $\begin{array}{c}85 \\
(69 \cdot 1 \%)\end{array}$ & 36 & 2 & 123 & $\begin{array}{c}27 \\
(90 \%)\end{array}$ & 3 & 0 & 30 \\
\hline Unknown & $\begin{array}{r}8 \\
(100 \%)\end{array}$ & 0 & 0 & 8 & 1 & 0 & 0 & 1 \\
\hline Total & $\begin{array}{c}39,467 \\
(93.6 \%)\end{array}$ & $\begin{array}{c}2557 \\
(6 \cdot 1 \%)\end{array}$ & $\begin{array}{c}156 \\
(0 \cdot 3 \%)\end{array}$ & 42,180 & $\begin{array}{c}13,093 \\
(98 \cdot 6 \%)\end{array}$ & $\begin{array}{c}182 \\
(1 \cdot 4 \%)\end{array}$ & $\begin{array}{c}8 \\
(<0.1 \%)\end{array}$ & 13,283 \\
\hline
\end{tabular}

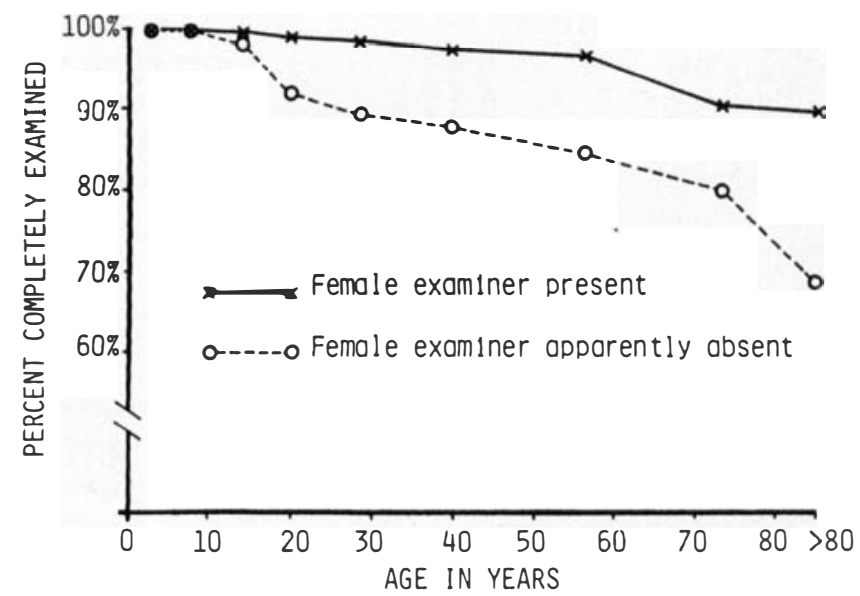

Figure 3. Completeness of examination of females in the presence or apparent absence of a female LCA. Examinations at which a medical officer was recorded as present are excluded. See Table 7. 


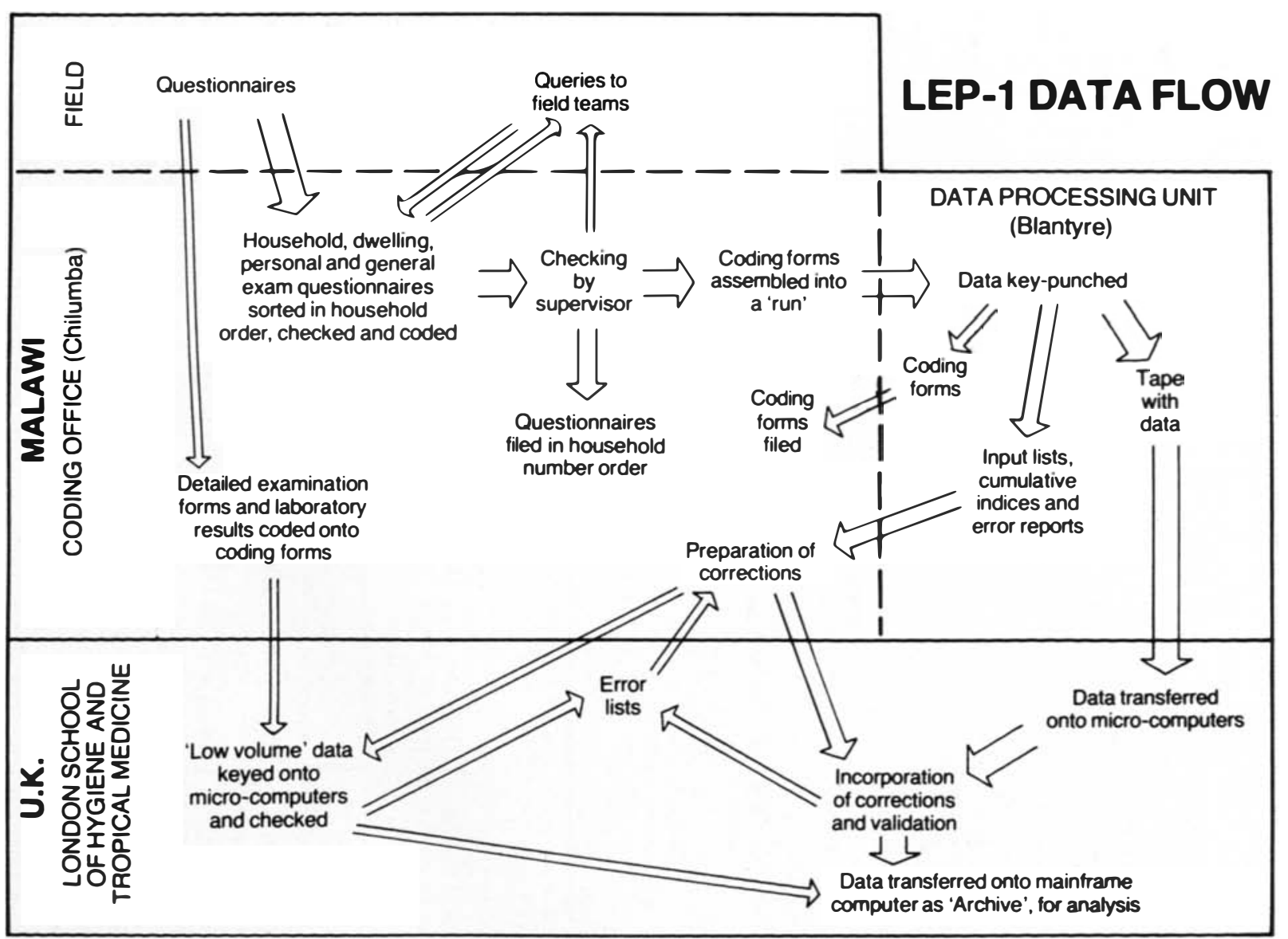

Figure 4. Diagram illustrating the flow of data from the field to and from Project Headquarters, in Chilumba, the Data Processing Unit in Blantyre and the London School of Hygiene and Tropical Medicine. Width of arrows corresponds roughly to volume of data concerned. 
The data were then coded from the field questionnaires onto corresponding coding forms and checked by JMP, IJS or a senior coder. Coding of Detailed Examination Form data was carried out almost exclusively by JMP.

Coding forms (except those for the Detailed Examination Forms and laboratory results) corresponding to approximately 2000 individuals were assembled each month and were sent together (as a 'run') to the Malawi Government Ministry of Finance Data Processing Unit (DPU) in Blantyre. The Detailed Examination coding forms and laboratory result coding forms were sent directly to the London School of Hygiene and Tropical Medicine.

At the DPU the data were key-punched onto tape, a copy of which was sent to the London School of Hygiene and Tropical Medicine. At the same time cumulative indices of individuals in identification number, name and village ordẹr were produced for use in the coding office in Chilumba. In addition an input listing of the 'run' and an error report were prepared and sent to Chilumba. This error report was scrutinized and corrections of mistakes (usually due to key punch errors) sent directly to the Project's programmer in London (LB).

After arrival in London the data were transferred from tape to microcomputers for correction. Instructions for corrections sent from Chilumba to London (prompted by the Blantyre error report or by errors detected in the coding office) were, and still are incorporated into the data, validated and additional error listings produced and sent back to Chilumba for further correction. At agreed intervals all data cleaned to a certain degree are archived on an Amdahl mainframe at the University of London Computer Centre and used for analyses.

All the data for each individual are linked via his or her unique IDENT number. All data entry programs incorporate the check digit algorithm (Table 3 ) in order to identify invalid IDENT numbers.

\section{Discussion}

Important criteria for the operational success of an epidemiological project are the quality and completeness of the field work. Incomplete data leave room for the possibility that the results are not representative.

In this survey $97.93 \%(110135 / 112759)$ of all individuals resident in the survey area and who were enumerated by the LEP teams were examined. We do not know how many residents in the survey area were never mentioned to or seen by us. Such missed individuals fall into 2 groups: (i) those who were resident in households which were completely missed, and (ii) those who were resident in households which were otherwise interviewed and examined.

The aerial photographs were 2 years old at the time of starting the main project. In so far as these photographs were used to identify houses, the chance of missing a household increased with time. In order to counteract this chance of missing households, the field staff routinely enquired whether there were any new households in an area. It is unlikely that many escaped attention.

Another problem is raised by complete households (and individuals) which moved, during the course of the survey, from an unexamined area into a village which had already been completely examined by one of our teams. This is a problem for any survey which requires a long period of time. Some of these households became known to us in so far as they were related to people interviewed and examined; but we do not know their exact number. Usually no efforts were made to trace, interview and examine them at their new place of residence. We expect to be able to estimate the frequency of such migration, and hence the number of missed households (and individuals), on the basis of the second survey begun in 1986. In any case, we doubt that many, if any, persons moved in order to avoid detection of disease; and thus this should not bias the data as far as leprosy is concerned. Little if any stigma is attached to the disease in this population.

Considerable effort was made to recognize individuals who had previously been identified in the survey, in order to avoid their receiving more than 1 identification number. As a matter of routine, 
the alphabetical name indices were consulted at the time of coding each individual. However, because of changes of first names, especially in young people, and because of the use of more than one surname, especially in the north of the district, the checking of alphabetical indices was not foolproof. For this reason, the year of joining a household, and the previous residence, were always asked with great care. If an individual was found to have joined a household after the beginning of the survey, it was routinely checked whether he or she had already been interviewed or examined previously. This was achieved by searching manually the records of all related households in the village from which he or she had come. The recording of scars and birthmarks on the general examination forms was of great help in confirming the identity of individuals. Parentage information was also very useful for tracing and identifying individuals in the records, though we appreciate that this information was not always 'correct'. In particular, brothers of the real father and sisters of the real mother were frequently cited as parents, in line with local custom, especially if the real parents were dead or absent.

The incorporation of check digits into the IDENTs (see Table 3), and their screening by all data entry programs, has proved extremely valuable in identifying transcription and keypunch errors with these crucial numbers.

The recording of examination results on separate forms for each individual encouraged thorough examination and facilitated supervision. LCAs who did not record scars and birthmarks were suspected to have become slack in their examinations and could be encouraged sooner than would have been possible otherwise.

As an additional quality control the MO reexamined several hundred individuals shortly after their examination by LCAs. However, such independent resurveys could not be organized on a scale large enough to provide a precise estimate of the frequency with which suspicious lesions were missed by the LCAs.

The relative incompleteness of examinations of older females, in particular by male staff, is a matter of considerable interest and concern to us. The difference shown in Table 6 is likely to be an underestimate in so far as a female LCA was present in an unknown percentage of examinations but remained uncoded. It is for this reason that the table speaks of the 'apparent' absence of female LCAs. How many leprosy lesions are likely to have been missed may become apparent once we have analysed the frequency distribution of lesions on different parts of the body of women examined by female staff. If single leprosy lesions are frequent on those parts of the body usually missed during incomplete examinations then we shall suspect that our estimates of the prevalence and incidence of leprosy in older females are underestimates. ${ }^{16}$ It should be noted that this is a widespread problem in leprosy work, in that most leprosy field workers are males and social taboos restrict their examining females in many societies. To what extent this difference may explain the reputed male excess of leprosy reported in many areas of the world has long been debated. ${ }^{17}$ The LEP data provide an opportunity to examine this subject.

The LEP was conceived as a longitudinal study to identify risk factors for the transmission of $M$. leprae and the development of clinical leprosy. The analysis of these factors has begun, in particular of BCG vaccination (as indicated by a post-vaccination scar), which has been shown to impart at least $50 \%$ protection against clinical leprosy in this population. ${ }^{18}$ In addition, while the first survey was in progress, it became apparent that the area was suitable for a leprosy vaccine trial. The 'Karonga Prevention Trial' (KPT) has thus been incorporated into the second survey. The main objectives for this trial are to see whether a combined vaccine including BCG and killed $M$. leprae imparts greater protection against leprosy than does BCG alone, and whether a repeat BCG with or without killed $M$. leprae improves the protection imparted by a single BCG vaccination. The results of this trial should become available after the third LEP survey (second KPT survey) in the mid1990s. 


\section{Acknowledgments}

The authors wish to thank the people of Karonga District, Northern Malawi for their co-operation, without which this study would not have taken place. All the LEP staff worked hard to carry the first survey through and we would like to mention at least those who were with the project from 1979 till the end of the first survey in August 1984: Mr W Twea (administrator), Mr S Malema, Mr F Ngosi, Mr G Kayesera, Mr B Mwamondwe (field staff), Mr M Kalambo (coding officer), Mr H Tegha (Lab Technician) and Mr F Mwangolowo (office staff). Some of the data processing procedures were initiated by $\mathbf{R}$ Norman, the project's first programmer.

JMP would like to express his sincere thanks to G Boerrigter for many valuable discussions and for his help during leave and illness. We would also like to thank Dr I M Ponnighaus for her considerable contribution to the preparation of corrections on the basis of the Blantyre and London error reports.

We thank N Maine for help with the tabulations and Judith Russell for preparation of the typescript.

Funding for the Lepra Evaluation project was provided primarily by the British Leprosy Relief Association (LEPRA) and we greatly appreciate their generous support for a project that initially grew like 'topsy'. A grant for the purchase of the microcomputers came from the Overseas Development Administration and statistical support was funded by the IMMLEP component of the Special Programme in Research and Training in Tropical Diseases of the UN Development Programme, World Bank and WHO. The authors would like to thank the Government of the Republic of Malawi for their interest in the project.

\section{References}

${ }^{1}$ Fine PEM. Problems in the collection and analysis of data in leprosy studies. Lepr Rev, 1981; 52: Suppl 1, 197-206.

2 Doull J Al, Rodriguez JN, Guinto R, et al. A field study leprosy in Cebu. Int J Lepr, 1936; 4: 141-70.

${ }^{3}$ Doull JA, Guinto RS, Rodriguez JN, et al. The incidence of leprosy in Cordova and Talisay, Phillippines. Int J Lepr, 1942; 10: 107-31.

4 Rao PSS, Karat ABA, Kaliaperumal VG, et al. Prevalence of leprosy in Gudiyatham Taluk, South India. Part I. Specific rates with reference to age, sex and type. Int J Lepr, 1972; 40: 157-63.

${ }^{5}$ Rao PSS, Karat ABA, Kaliaperumal VG, et al. Incidence of leprosy in Gudiyatham Taluk, South India. Indian J Med Res, 1972; 60: 97-105.

${ }^{6}$ Stanley SJ, Howland C, Stone MM, et al. BCG vaccination against leprosy in Uganda: final results. J Hyg (Camb), 1981; 87: 233-48.

7 Bechelli LM, Gallego Gabajosa P, Gyi MM, et al. Some epidemiological data on leprosy collected in a mass survey in Burma. Bull WHO, 1973; 58: 81-9.

${ }^{8}$ Dominguez VM, Gallego Gabajosa P, Gyi MM, et al. Some Epidemiological information on leprosy in the Singu area of upper Burma. Bull WHO, 1980; 58: 81-9.

9 Russel DA, Scott GC, Wigley SC. BCG vaccination in leprosy: a preliminary report of a 'blind' controlled trial. Int J Lepr, 1964; 32: 235-47.

${ }^{10}$ Irgens LM. Leprosy in Norway - an epidemiological study based on a national patient registry. Lepr Rev, 1980; 51: Suppl, 1-130.

11 Malawi Population Census 1977. Final Report Volume I, National Statistical Office, PO Box 333, Zomba. Printed by the Government Printer, Zomba, 1980.

12 Boerrigter G, Ponnighaus JM. 10 years leprosy control work in Malawii (Central Africa). Part one-methods and outcome after treatment. Lepr Rev, 1986; 57: 199-219.

13 Ridley DS. Therapeutic trials in leprosy using serial biopsies. Lepr Rev, 1958, 29: 45-52.

14 Rao PSS, Karat S. Epidemiological studies in leprosy in Gudiyatham Taluk. II. Patterns of familial aggregation of leprosy in an endemic area. Lepr Rev, 1969; 40: 93-8.

15 Ponnighaus JM, Fine PEM, Bliss L. Certainty levels in the diagnosis of leprosy (submitted for publication).

${ }^{16}$ Ponnighaus JM, Fine PEM, Maine N. The Lepra Evaluation Project, an epidemiological study of leprosy in Northern Malawii. II. A preliminary analysis of prevalence rates. Lepr Rev, 1988, 59:.

17 Fine PEM. Leprosy: The epidemiology of a slow bacterium. Epidemiologic Review's, 1982; 4: 161-87.

18 Fine PEM, Ponnighaus JM, Maine N, Clarkson JA, Bliss L. Protective efficacy of BCG against leprosy in Northern Malaŵi. Lancet, 1986; 2: 499-502. 


\section{China Leprosy Journal, Volume III, Number 1, March 1987}

It was a pleasure to receive yet another issue of this journal from China and to see the remarkable range of publications on leprosy from various parts of the country. This number includes an editorial on speeding up reform for the leprosy control system; original articles; articles from overseas; reports on leprosy control; clinical reports; short reports; study notes; translations from the world literature; letters to the Editor. The contents list is in English, as are also the summaries and authors names which are written in ping-ying. But the journal is otherwise entirely in Chinese and thus of somewhat limited value. Nevertheless this contact is important and gives clear evidence of wide-ranging interest from workers in many provinces where leprosy is still a problem. Published by the China Leprosy Association and China Leprosy Center, No 2, Huifuxi Road, Guangzhou, China.

\section{Early surgery in Hansen's neuritis; an illustrated manual}

Due to pressure of space, we have not been able to print formal reviews of publications in recent years, but we take this opportunity to thank the Associazione Italiana 'Amici di Raoul Follereau', Via Borselli 4, 40135 Bologna. Italy, for sending a copy of this hardbacked illustrated manual, with 80 pages and numerous colour pictures. Dr Silvano Renzo was formerly Chief Medical Officer of the National Leprosy Control Programme in Guinea Bissau. Dr Cesare Panciera is a physician specialist in orthopaedic and traumatic surgery in Treviso, Italy. After an introduction, the manual covers the neuritis of Hansen's disease and then proceeds to a description of the surgical procedures advised for entrapment syndromes. Apply to AI, at the address above.

\section{German Foundation for International Development}

This Foundation, in association with the Scientific Secretariat of the 17th International Congress of Dermatology (CMD), organized in Berlin (West), 20-23 May 1987, a pre-congress International Workshop on 'Dermatology in Basic Health Services' in an endeavour to assess the magnitude of skin diseases, leprosy and sexually transmitted diseases, to plan strategies for their control and to explore possibilities of cooperation between different countries.

Forty-six experts participated in the Workshop. Aside from dermatovenereologists, epidemiologists, public health experts, microbiologists and pharmacologists attended the meeting. Two practitioners-one each of Chinese and Indian systems of Medicine-were also invited. The participants represented 27 countries from Africa, Asia, Europe and North, Central and South America. Representatives of German Aid Agencies and WHO were also actively involved.

The meeting spread over 8 sessions on 4 days, discussed the magnitude and epidemiology of dermatology, leprosy and sexually transmitted diseases in the developing world. The participants emphasized that the pattern of skin diseases in the developing parts of Africa, Asia and Latin America indicate that about $30 \%$ of patients seeking medical help are suffering from skin affections. A majority of skin diseases are associated with poor socioeconomic conditions, lack of environmental and personal hygiene and inappropriate housing resulting in parasitic, bacterial and fungal infections which form the bulk of dermatological problems. The situation is further aggravated by the shortage of appropriately-trained manpower and financial constraints. Further information: Secretariat Deutsche Stiftung für internationale Entwicklung', Reiherwerder, D-1000 Berlin 27 (West), Germany

\section{Zambia: Bwino; Special Position Paper No 4. Leprosy Control}

Bwino is a health care magazine published by the Zambian Ministry of Health. The editorial group consists of Ministry of Health and National Food and Nutrition Commission staff. Each issue contains a number of articles but it is not possible to go into great detail. From time to time, therefore, it has been agreed to publish Position Papers to cover various topics in more depth. These papers, depending on the topic will be distributed among relevant institutions and we are particularly interested in reaching training establishments as well as the usual outlets for the magazine. It is hoped the information will stimulate thought on the way various issues are tackled in educational activities. Number 4 deals specifically with leprosy: Chapter I, Leprosy Control Policy; Chapter II, Diagnosis and Classification; Chapter III, Treatment; Chapter IV, Complications and their Management; Chapter V, Implementing full multiple drug therapy (MDT); Appendix I, Skin smear technique; Appendix II, Assessment and Discharge; Appendix III, Leprosy Patient Record Card MF 56; Appendix IV, Outpatient Record MF 68.

This issue in fact constitutes a working manual. It is extremely well presented, including several illustrations and charts and should be of great practical value to the control programme in Zambia. Further enquiries; Dr Richard de Soldenhoff, PO Box 30205, The Ministry of Health, Lusaka, Zambia. 